\title{
É imprescindível educar
}

\author{
integralmente
}

Ninguém escapa da educação. Em casa, na rua, na igreja ou na escola, de um modo ou de muitos, todos nós envolvemos pedaços da vida com ela: para aprender, para ensinar, para aprender e ensinar. Para saber, para fazer, para ser ou para conviver, todos os dias misturamos a vida com a educação.

CARLOS RodRIGUES BRANDÃo

\section{Uma aproximação conceitual e um novo debate}

aquecimento do debate em torno da educação integral nos anima a revisitar um estudo realizado pelo CENPEC, em 1999, ${ }^{1}$ atualizando a reflexão sobre o tema. Rediscutimos, neste texto, os diferentes conceitos de educação integral para, a partir dessa referência, refletir sobre o desafio da implantação dos programas de educação integral e das questões que mobilizam os ânimos a respeito do tema. Há muitos atores nessa reflexão: os especialistas, os agentes públicos da política educacional e a sociedade brasileira em geral parecem convergir na intenção de encontrar alternativas para a melhoria de educação das crianças brasileiras. A educação integral retorna à cena como uma delas.

Isoladamente, nenhuma norma legal, concepção ou área da política social dá conta do atendimento completo pretendido pelas propostas de educação integral. A perspectiva que adotamos é, portanto, a da necessidade de uma composição de estratégias e alternativas políticas e pedagógicas para repensarmos o modo de funcionamento das instituições educativas, a fim de colocá-las a favor da lógica da inclusão e da formação integral das crianças e adolescentes.

* ISa Maria F. Rosa Guará é Pedagoga, Doutora em Serviço Social (PUC/SP) e Pós-Graduada em Psicopedagogia. É Vice-Presidente da Fundação ABRINQ pelos Direitos da Criança e do Adolescente e Assessora de Coordenação do CENPEC. 
A construção de um pacto garantidor do esforço coletivo a favor da educação integral deve considerar a meta, sem pretender enquadrar as iniciativas regionais, o que supõe estimular soluções não homogeneizadoras, que respeitem os diferentes contextos e possibilidades.

Com diversas propostas políticas concretas sendo efetivadas por secretarias e órgãos públicos, em vários municípios e estados do País, a questão da educação integral tem alcançado maior visibilidade. Mas a concretização das propostas expõe os desafios da prática e faz emergir a necessidade de se estabelecer um patamar básico de compreensão do significado da experiência pretendida, alinhando entendimentos em torno da concepção que circula nas produções acadêmicas e nos programas políticos na área.

\section{Educação Integral como formação integral}

O que se observa nas discussões de vários autores, especialmente os clássicos da pedagogia, é que, quando se fala em educação integral, fala-se de uma concepção de ser humano que transcende as concepções redutoras que hoje predominam na educação, por exemplo, as que enfatizam apenas o homem cognitivo ou o homem afetivo. A integralidade da pessoa humana abarca a intersecção dos aspectos biológico-corporais, do movimento humano, da sociabilidade, da cognição, do afeto, da moralidade, em um contexto tempo-espacial. Um processo educativo que se pretenda "integral" trabalharia com todos estes aspectos de modo integrado - ou seja - a educação visaria à formação e ao desenvolvimento humano global e não apenas ao acúmulo informacional.

BERNARDETE GATTI

A concepção de educação integral que a associa à formação integral traz o sujeito para o centro das indagações e preocupações da educação. Agrega-se à idéia filosófica de homem integral, realçando a necessidade de desenvolvimento integrado de suas faculdades cognitivas, afetivas, corporais e espirituais, resgatando, como tarefa prioritária da educação, a formação do homem, compreendido em sua totalidade.

Na perspectiva de compreensão do homem como ser multidimensional, a educação deve responder a uma multiplicidade de exigências do próprio indivíduo e do contexto em que vive. Assim, a educação integral deve ter objetivos que construam relações na direção do aperfeiçoamento humano. Ao colocar o desenvolvimento humano como

\section{[...] a educação \\ deve responder a uma \\ multiplicidade de exigências do próprio indivíduo e do contexto em que vive.}

horizonte, aponta para a necessidade de realização das potencialidades de cada indivíduo, para que ele possa evoluir plenamente com a conjugação de suas capacidades, conectando as diversas dimensões do sujeito (cognitiva, afetiva, ética, social, lúdica, estética, física, biológica).

Esta perspectiva humanística da educação como formação integral sinaliza para relações educativas em que também o educador se desenvolva plenamente, para que possa compreender e dar significado ao processo educativo, como condição para a ampliação do desenvolvimento humano de seus educandos. Isso poderá favorecer uma prática pedagógica compreensiva do ser humano, em sua integralidade, suas múltiplas relações, dimensões e saberes, reconhecendo-o em sua singularidade e universalidade. A educação, como constituinte do processo de humanização, que se expressa por meio de mediações, assume papel central na organização da convivência do humano em suas relações e interações, matéria-prima da constituição da vida pessoal e social.

Em seu livro Reconstruir o ninho, Urie Bronfenbrenner estabelece cinco proposições que descrevem os processos que alimentam o desenvolvimento humano. No núcleo desses princípios, está a necessidade social, intelectual, física e emocional da criança de interação mútua e contínua com um adulto cuidadoso, afetivo e estimulador, preferivelmente, com muitos adultos. Uma de suas proposições define que:

... para que uma criança ou adolescente se desenvolva intelectualmente, emocionalmente, socialmente e moralmente, é preciso que participe progressivamente de atividades recíprocas complexas, de modo regular, pelo período de toda sua formação, relacionando-se com uma ou mais pessoas e estabelecendo, com elas, um vínculo emocional, mútuo e forte (Bronfenbrenner, 1990).

A idéia da formação integral do homem está presente, principalmente, em projetos de educação para a paz, dos direitos humanos e da educação para valores, todos eles fundamentados em princípios éticos e humanistas. 
Nesse sentido, a formação integral dos indivíduos não está adstrita ao processo formal e intencional de ensino, pois tem sua base nas esferas da vida cotidiana, como nos lembra Heller (1994). Inicia-se no nascimento e prossegue com a aprendizagem sobre o universo cultural, durante todo o processo de desenvolvimento das pessoas, pois é na vida cotidiana que se objetivam as ações humanas e nela se inscrevem os resultados do conhecimento humano, de suas conquistas e desafios.

\section{Educação integral como articulação de saberes a partir de projetos integradores}

A relação escola/comunidade também poderá propiciar o estudo dos temas transversais, a integração entre as disciplinas e o trabalho coletivo. Com efeito, quando o aluno aprende a conhecer a comunidade com suas variedades de aspectos e de tipos, passa a preocupar-se com seus problemas e, se bem orientado, passa a querer participar na resolução dos mesmos e, não raro, o aluno evolui quanto: ao respeito às manifestações culturais, à compreensão do lugar público e suas regras, à luta contra o preconceito, ao respeito alheio e a seu direito de ser respeitado enquanto cidadão [Udemo (s/d)].

Algumas concepções sobre a educação integral remetem à idéia de projetos que articulam saberes em diferentes contextos, ampliando o foco do processo para a rede de espaços de aprendizagem. Isso vale tanto para os projetos de trabalho no âmbito da escola quanto para aqueles desenvolvidos em outros contextos educativos. O centro das preocupações com a aprendizagem está em permitir que as vivências e a ação pedagógica, organizada por projetos, leve a uma integração dos conhecimentos e saberes tanto da esfera acadêmica quanto da vida social.

Toro define saber social como "o conjunto de conhecimentos, práticas, habilidades, ritos, mitos e valores que permitem que uma sociedade possa sobreviver conviver, produzir e dar sentido à vida" (Toro, 1998). A educação deve, portanto, considerar esses saberes que garantem aos homens sua sobrevivência, seus relacionamentos pessoais e sociais, seu trabalho produtivo e o sentido para sua vida. Essas são tarefas de toda uma vida. Para dar conta delas, há um conjunto de conhecimentos sistematizados e organizados no currículo escolar e também há as práticas, habilidades, costumes, crenças e valores que conformam a base da vida cotidiana e que, soma- dos ao saber acadêmico, constituem o currículo necessário à vida em sociedade.

No sistema educacional escolar, uma das alternativas de integração desses saberes é o método educativo de projetos de trabalho, proposto por Hernandez (1998), que vem sendo colocado como desafio investigativo aos estudantes, instigando-os a buscar soluções para as questões emergentes de sua realidade. A perspectiva adotada é a da articulação de conhecimentos que se constroem a partir de proposições e não de disciplinas escolares.

Nessa proposta, valorizam-se a imaginação e a criatividade também do educador, que deve manter-se em "estado-de-aprender", desenvolvendo suas competências e habilidades em diferentes abordagens. Já se reconhece a necessidade de interlocução com outras instituições socializadoras e educadoras, como a família, a igreja, as bibliotecas, os museus, os clubes esportivos, as organizações sociais e outros tantos espaços de aprendizagem que a cidade oferece.

Muitas organizações sociais dão ênfase à educação integral a partir de uma área ou tema do conhecimento, como eixo para o desenvolvimento de outras competências, em projetos apoiados em arte, esporte, lazer, meio ambiente, saúde, entre outros. Se, no currículo escolar, eles comparecem como temas transversais, aqui, constituem-se em temas centrais, a partir dos quais, são estabelecidas as conexões com outras demandas de conhecimento.

Os projetos de trabalho na escola, bem como os projetos temáticos nas organizações sociais, têm relação com o trabalho colaborativo em diversos ambientes de aprendizagem e procuram colocar o aluno como centro, desenvolvendo sua autonomia e sua socialização. Nas organizações não-governamentais, o desenvolvimento de projetos é facilitado pela natureza de seu espaço sociocultural mais flexível, que oferece suporte para a mediação entre a família, a escola e a comunidade, visando ao desenvolvimento global da criança e sua interação com o meio.

Se a dinâmica da socialização e os processos educacionais ocorrem em diferentes lugares, e de modos variados, a proposta de Educação Integral, como articulação de saberes a partir de projetos integradores, também aflui para a demanda de articulação das redes institucionais, que devem operar, de modo compartilhado e complementar, com os programas e as políticas dirigidas ao mesmo público de um mesmo contexto local. 


\section{Educação Integral na perspectiva de tempo integral}

Quanto à educação em horário integral, ela se configuraria como uma ampliação do tempo escolar diário, porém, não penso que deveria, esse tempo, ser utilizado na forma de horário disciplinar. Esta ampliação comportaria um processo educativo pensado segundo outras premissas, realizado por atividades, oficinas, experiências, onde (sic) os alunos pudessem trabalhar, não só com os saberes, mas com coisas, cultivar artes aplicadas, cultivar elementos artísticos, criar projetos e desenvolvêlos, sob orientação de profissionais diversificados.

BERNARDETE GATTI

Educação Integral aparece também na perspectiva de tempo integral de atendimento de crianças e jovens. Diversas experiências brasileiras de extensão da jornada escolar e de implantação de um período integral nas escolas públicas apresentam-se como propostas de educação integral. As duas experiências mais conhecidas de escola pública de tempo integral, no Brasil, são o projeto Escolaclasse e Escola Parque na Bahia, na década de 1950 (e, depois, no Distrito Federal), e, nos anos 1980, os Centros Integrados de Educação Pública - CIEPs, no Rio de Janeiro, cujo projeto foi repetido posteriormente nos Centros de Atenção Integral à Criança - CAIC, nos anos $1990 .^{2}$

Em São Paulo, foi realizado o Profic - Programa de Formação Integral da Criança, entre os anos de 1986 e 1993.0 programa conjugava diferentes projetos voltados para a formação integral, com a particularidade de se utilizar parcerias com as Prefeituras Municipais e com as organizações sociais locais, como uma estratégia de minimização dos custos e aproveitamento dos recursos existentes. Diferentemente das experiências dos CIEPs e dos CAICs, o Profic, desde sua implantação, substituiu a construção de prédios pelo uso dos espaços da escola e das entidades parceiras.

O objetivo dos programas de extensão do horário escolar era o de ministrar um ensino fundamental que abrangia atividades diversificadas, organizando-se a escola para dar, ao aluno, a oportunidade de uma escolarização formal ampliada por um conjunto de experiências esportivas, artísticas, recreativas ou temáticas, em complementação ao currículo escolar formal.

A descontinuidade desses programas é indicativa das dificuldades de implantação e até mesmo de aceitação dessas propostas. As críticas referem-se, sobretudo, aos dilemas da universalização, que inclui o tema da sustentabilidade das propostas em longo prazo, dúvidas sobre a qualidade do atendimento em tempo integral, problemas com a freqüência das crianças e questionamentos em relação à demanda de proteção social em contraponto à função da escola. É bem verdade que estamos em outro momento histórico, em que há uma disposição de aceitação e até mesmo um desejo social de programas de educação integral, mas é necessário que as questões possam ser colocadas para que as novas propostas encontrem bases mais seguras de aplicação.

Entre os consensos que prevalecem hoje sobre a educação, um dos mais fortes é o de que o tempo dedicado a ela está muito aquém do que seria necessário para dar conta da formação de nossas crianças e jovens para os desafios do século XXI. Há igualmente uma percepção de que as mudanças na família e na vida cotidiana exigem que a educação se amplie para atender a demandas anteriormente respondidas no âmbito doméstico ou comunitário. Outros países, especialmente os do Primeiro Mundo, já atendem com carga horária de seis ou oito horas. Escolas privadas brasileiras também começam a oferecer ensino em período completo, com o ensino regular complementado por atividades de acompanhamento pedagógico individualizado, recreação, oficinas e cursos variados, atividades na área esportiva, artística e ensino de línguas, além de passeios a museus, exposições e parques.

Se, para crianças e famílias da classe média, esse acesso, embora tenha um ônus orçamentário, pode ser facilitado, é justo que, sob o amparo da lei, que indica a obrigatoriedade da extensão do horário nas escolas públicas, acelerem-se as propostas de educação em tempo integral, em arranjos diferenciados de horários, metodologias e parcerias que também possam oferecer oportunidades educativas variadas para todas as crianças.

\section{Questões em debate na implementação de programas de Educação Integral}

Na implantação de projetos de Educação Integral, não há modelos prontos nem concepções exclusivas. Há um arco de opções e conjugações possíveis para diferentes contextos que permitem tanto a realização de projetos e programas pelo próprio sistema escolar, quanto por diversas áreas públicas atuando no espaço escolar ou, ainda, por diversas agências e organizações locais agindo complementarmente, em cooperação. Podem ter horários e agendas de aprendizagem peculiares, desde que baseadas nos parâmetros legais e em projetos pe- 


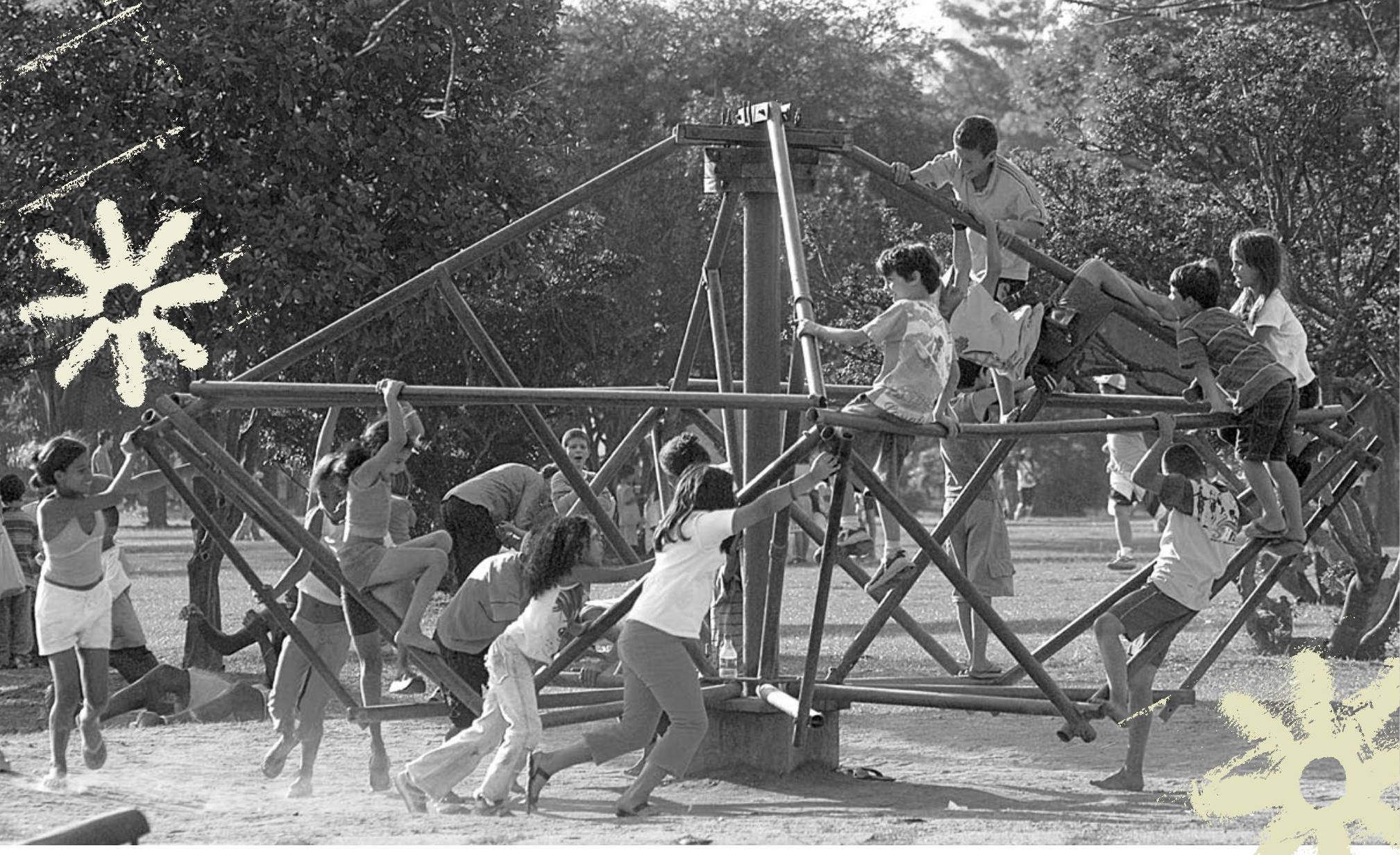

dagógicos adequados à sua realidade e às necessidades de suas crianças e jovens. Em todos os tipos e concepções de educação integral, há desafios a enfrentar e zelos que devem ser adotados nos planos e processos de ação. Discutiremos alguns deles.

\section{A difícil e necessária arte de integrar}

\section{Começamos esta reflexão lembrando que a educação} integral depende, sobretudo, de relações que visam à integração, seja de conteúdos, seja de projetos, seja de intenções. Num mundo cada vez mais complexo, a gestão das necessidades humanas e sociais exige a contribuição de múltiplos atores e sujeitos sociais, e uma nova cultura de articulação e a abertura dos projetos individuais para a composição com outros conhecimentos, programas e saberes.

Uma renovação nas atitudes, para socializar o poder, negociar, reconhecer e valorizar outros saberes, outros espaços e aceitar a incompletude, supõe mudanças que nem sempre são fáceis, porém produzirão resultados mais duradouros para os sujeitos envolvidos. Maria do Carmo B. Carvalho assegura que: "Somente a articulação/combinação de ações - entre políticas intersetoriais, intergovernamentais e entre agentes sociais - potencializa o desempenho da política pública. Arranca cada ação do seu isolamento e assegura uma intervenção agregadora, totalizante, includente" (CARVALHO, 2006).
Os novos relacionamentos necessários à integração de programas e ações devem estar impregnados pela idéia de colaboração e cooperação, e não pela de conflito e concorrência. Para superar divergências de opinião, interesses políticos setoriais, preconceitos e onipotências, os espíritos devem estar abertos às inovações, flexíveis na aceitação do outro e firmes na definição de metas voltadas para o interesse comum, cujo eixo central é o sujeito - criança e adolescente - em desenvolvimento.

A integração de professores, educadores, projetos e instituições tem a vantagem inegável de garantir maior sustentabilidade técnica e política e envolver a todos num compromisso de participação mais ativa e próxima. Considerando os objetivos colimados pelos que se propõem a programar ações públicas de educação integral, todo esforço deve ser empreendido no sentido de sustentar a integração dos projetos, programas, conteúdos, disciplinas e intenções para que, de fato, se consiga assegurar uma política pública regular e permanente que não sucumba às vicissitudes das novas administrações. Nesse aspecto, a presença da sociedade civil organizada, como parceira de empreitada, ajuda muito a dar sustentação institucional aos programas.

São fatores facilitadores dessa legitimação: a credibilidade social que a proposta alcance, o respeito à autonomia dos envolvidos, a clara definição de papéis e responsabilidades das organizações ou pessoas participan- 
tes, o planejamento e a realização conjunta de ações e a adoção de um processo mais participativo dos beneficiários no planejamento do trabalho.

\section{Educação Integral e inclusão social}

Todos podem aprender independentemente de seus pontos de partida, dos saberes que já têm sobre determinado objeto do conhecimento. Todos precisam ter o direito de experimentar aprendizagens bem-sucedidas; aprender a ter prazer em conhecer, em saber fazer, em produzir, em viver com os outros.

MARIA CRISTINA ZELMANOVITS

Podemos falar de inclusão olhando a partir de seu contrário: a exclusão. Há diversos olhares sobre a exclusão que a situam como um processo de apartação social e intolerância, como decorrência da discriminação dos sujeitos que apresentam fragilidades ou vulnerabilidades pessoais ou sociais, como não-aceitação das diferenças de gênero, etnia, religião etc. ou como resultado da situação de pobreza. Vamos aqui focalizar nossa atenção nesta ultima visão.

A população das escolas públicas que mais demandam uma educação integral é constituída, em parte, pela infanto-adolescência, cujas famílias ainda se mantêm em situação de pobreza. Por isso, a educação integral precisa ser conjugada com a proteção social, o que supõe pensar em políticas concertadas que considerem, além da educação, outras demandas dos sujeitos, sendo, a mais básica, a de uma sobrevivência digna e segura.

Programas e benefícios sociais como a merenda escolar, o “Bolsa-família”, o Programa de Erradicação do TrabaIho Infantil - PETI, entre outros, já associados à educação, podem oferecer condições para que as crianças freqüentem e permaneçam na escola, embora sejam insuficientes para assegurar resultados em aprendizagem. Além disso, o aumento do tempo de estudo deve vir acompanhado da ampliação do acesso das crianças e adolescentes aos espaços múltiplos de apropriação da cidade e de seus saberes, para que não se engessem as opções num projeto educativo regulado por oportunidades limitadas.

$\mathrm{Na}$ linha de prioridades, portanto, o investimento em programas que produzam eqüidade é um requerimento básico. No entanto, considerando a histórica herança assistencialista, é preciso que se fique alerta para o risco de diminuição da qualidade desses programas, provocada pelo ausente ou insuficiente provimento de recur- sos para os serviços oferecidos, o que inviabiliza a colaboração de profissionais bem preparados para a tarefa educativa. Se a população é vulnerável, precisará ainda mais de programas competentes e bem estruturados, cujo custo é certamente maior.

O movimento de inclusão de todas as crianças no mundo do conhecimento supõe, sobretudo, que o educador compreenda que qualquer criança é um ser em desenvolvimento e que articule ajuda para promover esse desenvolvimento, dispondo-se a aprender ou rever suas estratégias pedagógicas, para acolher, ensinar e estimular a todos a crescer em suas competências e talentos.

\section{Educação Integral, obrigação legal e escolhas familiares}

Podemos pensar a Educação Integral pela ótica do direito, considerando que a Constituição Brasileira, o Estatuto da Criança e do Adolescente - ECA e a Lei de Diretrizes e Bases da Educação Nacional - LDB indicam a obrigatoriedade da oferta pública de educação para todas as crianças e adolescentes. Assim sendo, a educação integral se assenta na concepção de proteção integral definida legalmente, que reconhece a situação peculiar de desenvolvimento da criança e exige uma forma específica de proteção, traduzida em direitos tanto individuais qunato coletivos, que possam assegurar seu pleno desenvolvimento.

Mais ainda, ao propor um novo sistema articulado e integrado de atenção a todas as necessidades da criança e do adolescente e a garantia de seus direitos, o ECA busca agregar compartimentos estanques de poderes e de saberes em torno de um destinatário especial. Neste sentido, procura retotalizar a criança, oferecendo-lhe uma proteção legal como base importante para a integração de políticas e programas de atenção.

A educação é um direito público subjetivo - aquele que o sujeito pode exigir diretamente do Estado -, o que permite garantia de acesso e permanência na escola. No que diz respeito ao acesso, o sistema público de educação tem se organizado, não sem muitas dificuldades, para atender à diversidade da população infantojuvenil, incluindo grupos especiais, como os portadores de deficiência, as crianças em situação de rua, os adolescentes que trabalham e os que moram em locais distantes. Embora o número de matrículas, divulgado pelo governo, bordeje a universalização ( $97 \%)$, sabemos que há hiatos e discrepâncias regionais nesse atendimento. 


\section{[...] há, nas familias, o desejo de que o tempo maior de estudo seja uma abertura às oportunidades de aprendizagem}

Quanto ao direito à permanência, a lei deixa subentender que o sistema público escolar deve encontrar metodologias e ferramentas pedagógicas que promovam condições para que o alunado se mantenha na escola e conclua com sucesso sua formação.

Do ponto de vista das famílias, o direito à educação gera uma obrigatoriedade, dos pais, de garantir que a criança freqüente a escola, e, das crianças, de freqüentá-la. Pela Constituição Federal - Artigo 208 - e LDB Artigo $4^{\circ}-$, o ensino fundamental é obrigatório. Liberati (2004) considera que:

Aos pais estão reservados dois papéis: o de atores de direitos e o de atores de obrigações. Como atores de direitos podem, em nome próprio ou de seus filhos, exigir sua intervenção nos processos pedagógicos, na discussão dos conteúdos curriculares, na inclusão de seus filhos em programas suplementares de transporte escolar, de material didático-escolar ou de merenda, e mesmo em atividades de gestão escolar [...] Por outro lado, são os pais, de igual modo, atores de obrigações, como [...] o dever de matrícula e de zelo pela freqüência, mas também de acompanhamento do nível de aprendizagem e de sociabilidade de seus filhos [...].

A previsão da LDB - Artigo 34 - de ampliação da permanência da criança na escola, com a progressiva extensão do horário escolar, gera, portanto, a mesma obrigatoriedade dos pais em garantir a freqüência dos filhos durante todo o período na escola. Entretanto, inúmeras pesquisas (Maurício, 2004; Cavaliere, 2002; Vandell, 2005) reafirmam a dificuldade de freqüência das crianças na escola para além de um período. A escolha das crianças e adolescentes, estes últimos principalmente, parece ser a de freqüentar diferentes espaços formativos da comunidade que ofereçam novas relações sociais e atividades mais sintonizadas aos seus interesses de desenvolvimento pessoal, principalmente aquelas ligadas à arte, línguas, esportes, grupos religiosos etc...

Muitos pais, por outro lado, preferem que seus filhos retornem ao lar, seja para assumir deveres domésticos, seja para o convívio em família. O saudosismo dos velhos tempos, da vida urbana mais tranqüila e de uma estrutura social em que o lugar da mulher era no lar, dedicada à educação dos filhos, pode nos levar a crer que seria bom reservar tempo para outras formas de convívio da família com os filhos, seja na própria casa, na vizinhança ou em atividades não regulares da comunidade.

O tempo livre da criança, quando encontra um bom ambiente educativo no círculo familiar, pode ser ocupado com vivências prazerosas de brincadeira e lazer que têm importância capital para seu desenvolvimento emocional. Parece-nos, entretanto, que, em muitos casos, por diversos motivos, a família nem sempre está presente e o "grande educador" passa a ser o aparelho de televisão ou o computador. Pesquisa realizada pelo Unicef (2001) mostra que pré-adolescentes e adolescentes passam de quatro a seis horas por dia vendo televisão e que quase $70 \%$ desta população não têm hábito regular de leitura.

A liberdade de escolha das famílias e dos estudantes, em relação à educação integral, é uma questão que merece reflexão e está relacionada a fatores como o tempo de estudo supervisionado e os conteúdos ou atividades oferecidas. Por outro lado, interessa muito, à maioria dos pais, que a criança permaneça sob os cuidados de uma equipe pedagógica. Como nos adverte Mauricio (2002), os pais priorizam a escola de horário integral; esta opção é fruto de uma avaliação refletida e não de um interesse menor de fazer uso da escola como compensação para as carências familiares.

Embora a educação integral apareça no imaginário popular como uma alternativa de prevenção ao desamparo das ruas e como programa de proteção social, além da expectativa de cuidado e proteção de seus filhos, há, nas famílias, o desejo de que o tempo maior de estudo seja uma abertura às oportunidades de aprendizagem, que são negadas para grande parte da população infanto-juvenil em situação de pobreza ou de risco pessoal e social.

\section{0 orçamento da educação}

\section{Novas pautas de luta pela melhoria da educação se atêm}

agora na busca de ampliação dos recursos orçamentários, como a que vem sendo coordenada pelo movimento da Campanha Nacional pelo Direito à Educação e pela mobilização pela aprovação do Fundeb, que estenderá os benefícios do financiamento para os grupos pré-escolares e do ensino médio. $E$ aí se introduzem dois dos 
pontos da discussão sobre educação integral: sua sustentabilidade e continuidade.

Uma das críticas mais habituais às propostas de educação integral é a que se refere aos custos dos programas. Mauricio (2004) nos mostra que o "custo aluno" nas escolas de período integral no Rio de Janeiro é maior que o da escola convencional, mas salienta que a educação dever ser considerada um investimento e não uma despesa. Anísio Teixeira (apud Cordeiro, 2001), falando na inauguração do Centro Popular de Educação Carneiro Ribeiro, em Salvador, lembrava que o projeto "era custoso e caro, porque eram custosos e caros os objetivos a que visava" e que "não se poderia fazer educação barata". Na experiência do Profic, em São Paulo, um dos aspectos justificadores da suspensão do programa refere-se aos custos de implementação e manutenção.

A questão dos custos esbarra ainda na demanda de universalização. Sendo direito de todos, a educação integral poderá ser requerida igualmente por todos, mas, como sabemos, os limites orçamentários para a cobertura universal são reais. Em geral, as experiências começam com escolas-piloto e não conseguem ser expandidas a todo o sistema educativo. Esta dificuldade inicial de universalização do atendimento integral não pode prescindir, portanto, de algum nível de negociação com as comunidades sobre os critérios de escolha dos beneficiados mais imediatos e do asseguramento da incorporação gradual dos interessados em novas unidades, que atuem na proposta de educação integral.

Esse gradualismo poderá levar em conta a escolha das famílias e crianças e, assim, possibilitar a expansão realista do sistema até que o maior número possível de crianças a ele tenha acesso. Trata-se de pensar a universalização como oportunidade e não como uma imposição às famílias.

Com a previsão de extensão do horário escolar, há custos complementares com a alimentação, além das despesas de manutenção geral e aquelas decorrentes da contratação de um número maior de educadores ou professores. O partilhamento de despesas e responsabilidades entre os governos estaduais e municipais, bem como entre secretarias e outros parceiros contribuintes, pode vir a ser uma alternativa de viabilização mais rápida dos projetos de educação integral.

\section{Integralidade e institucionalização}

\section{Um outro eixo de reflexão é o que discute a vinculação} da educação integral à idéia de institucionalização, alertando para o risco de que a escola de tempo integral possa escorregar para uma proposta de completude, tornando-se o que Foucault denunciou como instituição total (Foucault, 1993). Assim, a tentação de prover, num único espaço, atividades que atendam a todas as necessidades da criança: escolarização, esporte, artes, religiosidade, assistência, saúde etc., embora seja, certamente, mais confortável, tende a ancorar uma tendência de carregar, para o ambiente, a disciplinarização entorpecedora do desenvolvimento humano criativo e autônomo. Além disso, o tempo pedagógico regulado da escola, ou de um único programa complementar, leva a uma limitação de contatos e alternativas.

A submissão dos alunos a práticas espaço-temporais de contenção e massificação, na perspectiva da disciplinarização como estratégia educativa, tem produzido poucos resultados em termos de motivação e interesse pela aprendizagem. De igual modo, a ausência de supervisão educativa pode ser sentida, pelos alunos, como abandono e facilmente levá-los a se evadirem das atividades.

Para se evitar o risco da massificação dos programas que propugnam pela extensão do horário escolar ou turno completo, eles devem considerar, em seu currículo, diversas possibilidades de composição de atividades que incluam sempre a freqüência regular a recursos externos ou, ao menos, a presença, nas escolas, de grupos pertencentes a outras áreas da política social ou especialidades, visando oxigenar as estruturas homogêneas do sistema que devem permear-se a outras influências e relações. Assim sendo, cumpre lembrar que a tarefa educativa na escola, ou em consórcio entre a escola e outras organizações sociais na comunidade, precisa buscar a diversificação. Mas essa possibilidade de freqüência a muitos espaços de aprendizagem deve ser pautada por um nível de segurança adequado para a movimentação das diferentes faixas etárias e grupos, entre os espaços educativos oferecidos.

\section{Muitos espaços para aprender}

\section{Consideramos, nas reflexões deste texto, as diferentes} concepções, desafios e possibilidades de uma educação integral. Queremos pensar, finalmente, de modo mais específico, sobre as possibilidades de se oferecer às crianças uma alternativa que conjugue o ensino for- 
mal regular a outros espaços de aprendizagem, pressupondo que qualquer espaço que se pretende educativo só ganha sentido quando recheado pela relação educativa entre crianças e educadores.

Estamos falando dos espaços institucionais públicos, existentes nas comunidades, que vão desde as bibliotecas, os museus, os parques, os centros esportivos, aos cursos diversos de informática ou formação profissional. Este mosaico de ofertas pode se constituir em uma rede de aprendizagem importante e variada, mas, na maioria das comunidades que mais se beneficiariam desses recursos, eles, na verdade, não estão disponíveis e/ou não podem ser acessados. As distâncias e o preço do transporte para chegar a eles (que, em geral, se localizam nos centros urbanos ou em cidades maiores) dificultam objetivamente a presença das crianças e jovens das escolas públicas nesses locais.

Os equipamentos mais presentes nas pequenas comunidades e nos bairros mais afastados são as igrejas, os centros comunitários e os núcleos socioeducativos. Existem ainda iniciativas não institucionais que brotam da boa vontade de cidadãos locais que organizam, a seu modo, grupos de dança ou capoeira, teatro ou outra atividade que possa interessar a algumas pessoas.

É nesses lugares que as crianças mais vulneráveis e suas famílias conseguem sentir-se acolhidos e desenvolver alguma atividade de convivência social ou de aprendizagem. No mapeamento das relações educativas mais significativas, é bem provável que as crianças se refiram a esses lugares como referências básicas em sua trajetória de vida.

Na perspectiva da educação integral, são os núcleos socioeducativos os que apresentam as características que permitem uma articulação efetiva com as escolas próximas e que, portanto, podem começar a tecer os fios de uma rede maior de recursos que favoreçam o desenvolvimento das crianças. Identificamos aqui, como núcleos socioeducativos, aquelas organizações sociais que desenvolvem projetos educativos no contra-turno escolar, atendendo a crianças e adolescentes em atividades diversas e promovendo seu acesso a outros recursos e benefícios disponíveis.

Há poucos anos, havia uma distância muito grande entre o discurso da escola formal e da educação que acontece nos espaços não-escolares. Hoje, há uma proximidade maior nessa conversa, facilitada pela implementação efetiva de políticas públicas integradas nas áreas de educação e assistência social e pelo reconhecimento público do traba-
Iho socioeducativo que vem sendo desenvolvido pelas inúmeras organizações e grupos sociais em todo o Brasil.

0 contato dos alunos com essas iniciativas diversificadas cresce a cada dia, porque responde a uma demanda de presença educativa além da escola e oferece canais para que essas crianças e jovens acessem serviços de assistência social, saúde, esportes etc., que, de outra forma, não conseguiriam. Com forte vinculação com a comunidade, as organizações sociais têm possibilidade de responder rapidamente às necessidades emergentes de proteção social. Como não têm um compromisso curricular específico e nem a avaliação de performance acadêmica, essas iniciativas podem experimentar inovações metodológicas ou pautas temáticas que atendam aos interesses de grupos específicos de modo mais flexível.

Apesar da fragilidade e da irregularidade na manutenção das atividades por falta de financiamento adequado, essas organizações sociais conseguem estabelecer, de modo mais personalizado, os elos entre o conteúdo escolar e a vida prática. Certas organizações são discriminadas por alguns críticos devido à sua atuação assistencialista, mas há, atualmente, uma profissionalização crescente na área, o que as qualifica como interlocutoras legítimas para o estabelecimento de parcerias que podem resultar em projetos conjuntos entre elas e a escola, superando as barreiras setoriais e corporativas e as resistências de parte a parte.

Com sua diversidade e sua capacidade de oferecer respostas criativas em muitas áreas, é razoável acreditar que essas organizações e a escola possam realizar diversos arranjos na viabilização da educação integral.

Pesquisas recentes em projetos de pós-escola nos Estados Unidos (Vandell, 2005), com crianças do ensino elementar e médio, apontam descobertas interessantes sobre esses programas: constatou-se que a opção dos alunos tem sido a de construir uma agenda própria que envolve a vinculação ao programa socioeducativo em uma organização social, complementada pela freqüência a diversos outros lugares em que têm interesse especial, como clubes, agremiações esportivas, aulas de música ou dança, atividades religiosas etc. Esses arranjos são especialmente preferidos pelos adolescentes mais velhos que têm maior segurança em se movimentar na cidade.

Para as escolas, o contato com os projetos socioeducativos pode significar uma aproximação do currículo ao contexto da vida e provavelmente conduzirá a uma inversão das prioridades curriculares, trazendo, para o primeiro plano das preocupações educativas, aqueles temas hoje 
colocados em segundo plano pelas disciplinas clássicas, freqüentando-as complementarmente como eixos transversais. Isso não significaria desatender à missão básica da escola, que é a de ensinar os alunos a aprender e garantir plena condição de leitura e compreensão do mundo, mas que esta situação ganhe um novo sentido pessoal, social e político para os cidadãos que se educam. Sobretudo, que se possam articular nexos entre a racionalidade e a vida cotidiana, por meio de um conjunto de saberes sistematizados e outros ainda inconclusos, em contínua elaboração pelos sujeitos.

As mudanças que hoje se insinuam pretendem contribuir para a melhoria da qualidade da educação. Sabemos que isso depende de fatores como o financiamento, o conhecimento científico, os recursos metodológicos disponíveis, a formação profissional básica e contínua dos educadores, o acompanhamento dos resultados do rendimento escolar, o domínio pleno da leitura e da escrita pelos alunos, a participação dos pais e da comunidade na escola e a criação de um ambiente escolar desafiador para a aprendizagem e favorecedor de processos de socialização, baseados em valores fundamentais da convivência humana.

Sabemos também que apenas a ampliação do horário escolar não garante a qualidade nem a eficácia necessária, e que será preciso uma mobilização de esforços e de vontades muito mais abrangente para assegurar o direito, de todas as crianças e jovens, ao mundo do conhecimento, ao exercício de suas habilidades e ao desenvolvimento humano e social.

Talvez a educação integral precise de novos protagonistas que sejam capazes de atender a demandas de saberes ainda invisíveis, como quer Morin (2000), para se ter uma visão capaz de situar o conjunto, o conhecimento pertinente e transformar o currículo fragmentado em um roteiro de aprendizagens novas e interessantes para a população infanto-juvenil deste futuro que já chegou.

Sinais animadores estão surgindo das ações educativas, revalorizadas pela vinculação da escola com o território, com a criação de comunidades de aprendizagem que se ampliam com o conceito de cidade educadora. São possibilidades de inovação temática e metodológica que, aliadas às mudanças político-estratégicas, podem ajudar a superar os velhos problemas da educação escolar e do sistema de ensino.

\section{Bibliografia}

ASSMANN, Hugo. Reencantar a educação: rumo à sociedade aprendente. 2. ed. Petrópolis: Vozes, 1998.

CenPEC - Centro de Estudos e Pesquisas em Educação, Cultura e Ação Comunitária. Relatório do Projeto Educação Integral, 1999.

CORDEIRO, Célia Maria Ferreira. Anísio Teixeira, uma "visão" do futuro. Estudos Avançados, v. 15, n. 42, p. 241-258, maio/ago. 2001. ISSN 0103-4014.

DELORS, Jacques. Educação, um tesouro a descobrir. In: Relatório para a Unesco da Comissão Internacional sobre Educação para o Século XXI. São Paulo: Cortez, 1998.

FAZENDA, Ivani. Interdisciplinaridade: história, teoria e pesquisa. 2. ed. São Paulo: Ed. Papirus, 1995.

FOUCAULT, M. Vigiar e Punir: nascimento da prisão. Trad. Lígia M. Pondé Vassallo. Petrópolis: Vozes, 1993. 277p.

FREITAG, Bárbara. $O$ indivíduo em formação: diálogos interdisciplinares sobre educação. 3. ed. São Paulo: Cortez, 1994.

GADOTI, Moacir. Interdisciplinaridade, atitude e método. São Paulo: Instituto Paulo Freire; Universidade de São Paulo, s/d. Disponível em: 〈http://www. paulofreire.org/Moacir_Gadotti/Artigos/Portugues/Filosofia_da_Educacao/ Interdisci_Atitude_Metodo_1999.pdf >.

HELLER, A. Sociologia de la vida cotidiana. 4. ed. Barcelona: Península, 1994.

INSTITUTO PAULO FREIRE. Inter-Transdisciplinaridade e Transversalidade. Programa de Educação Continuada. Disponível em: 〈http://www.inclusao.com. br/projeto_textos_48.htm>.

MAURÍCIO, Lucia Velloso. Literatura e representações da escola pública de horário integral. Revista Brasileira de Educação, n. 27, 2004. Disponível em: «http://www. anped.org.br/rbe27/anped-n27-arto3.pdf). Acesso em: 22 maio 2006.

MORA, Victor R. H. Etica y Educación Integral. Universidad de Santiago de Chile. Disponivel em: 〈http://www.bu.edu/wcp/Papers/Educ/EducHuaq.htm〉.

MORIN. Edgar. Os sete saberes necessários à educação do futuro. Síntese. Disponivel em: 〈http://www.centrorefeducacional.pro.br/setesaberes.htm〉. Publicado em: jul. 2000.

PIAGET, Jean. Psicologia e epistemologia: por uma teoria do conhecimento. Rio de Janeiro: Forense, 1973.

PIPITONE, Maria Angélica P. Programa de Formação Integral da Criança - Profic - da proposta teórica à implementação: o caso de Piracicaba-SP. 1991. Dissertação (Mestrado) - Programa de Pós-Graduação em Educação, UFSCar, 1991.

SAMARTINI, Luci Silva. O programa de formação integral - Profic: um espaço na escola pública. [s.d.]. Dissertação (Mestrado), PUC-SP, São Paulo, [s.d.].

TORO, Bernardo. Educação, conhecimento e mobilização. Palestra realizada no CenPeC, 1998.

UNESCO. Declaração Mundial sobre Educação para Todos. 1990. Disponível em: $\langle$ 〈ttp://www.dominiopublico.gov.br/download/texto/ueoo0108.pdf〉.

VANDELL, Deborah Lowe et al. The study of promising after-school programs: examination of intermediate outcomes in year 2. March, 2005. Disponivel em:/http://www.wcer.wisc.edu/childcare/pdf/pp/year2_executive_summary_and_brief_report.pdf $\rangle$.

UDEMO. Sindicato de Especialistas de Educação do Magistério Oficial do Estado de São Paulo. Jornal do projeto pedagógico, [s/d]. Disponível em: «http://www. udemo.org.br/JornalPP_01_05TemasTransversais.htm〉.

\section{Notas}

1 Em 1999, o CENPEC - Centro de Estudos e Pesquisas em Educação, Cultura e Ação Comunitária - realizou um levantamento bibliográfico sobre Educação Integral, como estratégia para o planejamento do Seminário de Educação Integral e como uma aproximação teórico-conceitual ao tema. 0 relatório final deste estudo, elaborado por Marco Antonio Dib, Joana Coutinho e Alice Quadrado, serve de base às reflexões deste texto.

2 Há ampla bibliografia analítica sobre as experiências dos CIEPS, apontando as críticas, desafios e acertos da proposta. Alguns desses textos encontramse neste CADERNO e outros podem ser pesquisados na bibliografia deste artigo. 